Acta Cryst. (1985). C41, 1-4

\title{
Checklist for Authors of Papers Submitted to Acta Crystallographica, Section C
}

\section{Short-Format Papers - a New Section}

Papers are considered for publication in Section C that report the results of one or more crystal structure determinations and that are primarily concerned only with the crystal and molecular structure results.

Following recent decisions by the Commission on Journals, Acta Crystallographica, Section C is to be divided into two parts. The format of papers for publication in the first part will remain essentially identical with that currently used for Section $C$ papers. The second part, to be entitled Short-Format Papers, will include shorter papers that will differ from the current format in having neither Introduction nor Discussion sections (i.e. they shall comprise only Abstract, Experimental, tables and figures, and Related literature). The structural criteria for both parts will be identical. Concise presentation is essential in either format. There are some additional changes affecting the form of the title and the content of the Abstract and Experimental sections (see below).

Papers submitted for consideration in Acta Crystallographica, Section C, subject to the Co-editor's discretion, should conform with the following arrangement:

The Title should be both short and informative and not include long compound names. It should relate the structure to the chemical or other interest in the crystal, e.g. 'The structure of a morphine derivative .......

The Abstract should consist of the information given in $\S(d)$ of the checklist below (in abbreviated telegraphic form and preferably in the order given).

The Introduction (not applicable to Short-Format Papers) should briefly state the reason for undertaking the structure determination and its chemical, physical, biological or other interest. If organic, or containing complicated organic ligands, a display of the structural formula of the material studied should be given, in accordance with IUPAC convention.

The Experimental section should include the information in $\S(e)$ of the checklist below, either in tabular or abbreviated telegraphic form. Any further details, say of refinement, should be treated as normal text, but kept as brief as possible. The Experimental will generally include not more than two tables and two figures per structure as described in $\$ 2.1$ of Notes for Authors [Acta Cryst. (1983). A39, 174-186]. Additional tables and figures may be deposited. If the table of bond distances and angles is very long, this will be deposited and only values that are unusual and relevant to the discussion will be retained for publication.
The Discussion (not applicable to Short-Format Papers) should include comment on any unusual features of coordination, bonding, bond lengths, bond angles, thermal vibrations etc.

Attention is drawn to the Suggested guidelines for the publication of Rietveld analyses and pattern decomposition studies [J. Appl. Cryst. (1982). 15, 357-359] and to Recommendations of the Ad-hoc Committee on Criteria for Publication of Charge Density Studies [J. Appl. Cryst. (1984). 17, 369]. Determinations based on powder data should be accompanied by copies of the data in the appropriate format (see Notes for Authors, Appendix III); these will be deposited both with the JCPDS, Swarthmore, and at the Union's office in Chester. Papers on polytypes will be treated no differently from those on other materials and basic diffraction data relating to these should be made available either for publication or for deposition. Recommended techniques for improving the standard of many crystal structure investigations will be published in Acta Cryst. (1985). C41, 301-303.

The checklist below is provided for the convenience of authors submitting papers for publication in Section C. Fuller information is given in Notes for Authors. Checklists for authors of papers submitted to Sections A and B of Acta Crystallographica and to Journal of Applied Crystallography are given in the first issue of those journals for 1985.

All papers submitted for publication in Acta Crystallographica, Section $\mathrm{C}$, should be checked against the following list:

(a) Signed Transfer of Copyright form with manuscript

(b) Typescripts

Submitted in triplicate to any Co-editor

Double-spaced with wide margins $($ e.g. $30 \mathrm{~mm})$

Authors' addresses in full

Maximum of 4000 words for full articles on a single structure, 2500 words for each additional structure determination

Maximum of 2000 words for Short-Format Papers

Maximum of 1000 words for Short Communications

(For typography see Notes for Authors, §9)

(c) Title

Short, informative and related to the chemistry or other relevant interest in the compound

Not to include long compound names 
(d) Abstract

Suitable for reproduction by abstracting services without change of wording

Any references to be given in full

To include:

Systematic IUPAC name

Chemical formula

Formula weight

Space group

Unit-cell dimensions

Volume of unit cell $\left(\AA^{3}\right)$

$Z$

Measured and calculated densities $D_{m}, D_{x}$

Radiation and wavelength

Linear absorption coefficient

$F(000)$

Temperature of measurement

Final value of $R=\left[\sum\left(\left|F_{o}\right|-\left|F_{c}\right| \mid\right) / \sum\left|F_{o}\right|\right]$ and number of unique reflections

Discussion of principal structural results (in about 50 additional words)

(e) Experimental section

To include:

Source of material

Crystal shape and size

Method of measuring $D_{m}$

Diffractometer used

Method of measuring intensities

Number and $\theta$ range of reflections used for measuring lattice parameters

Absorption correction applied (with maximum and minimum values)

Maximum value of $(\sin \theta) / \lambda$ reached in intensity measurements

Range of $h, k$ and $l$

Standard reflections and their intensity variation throughout experiment

Number of reflections measured

Number of unique reflections

Value of $R_{\text {int }}\left[\sum|F-\langle F\rangle| / \sum F\right.$, from merging equivalent reflections]

Number of unobserved reflections

Criterion for recognizing unobserved reflections $[I<n \sigma(I)]$

Method used to solve structure

Definition of origin for polar structures

Independent physical measurements made to check polarity or chirality as applicable

Use of $F$ or $F^{2}$ magnitudes in least-squares refinement

Methods of locating and refining $\mathrm{H}$ atoms if applicable

Parameters refined

Values of $R, \quad w R=\left[\sum w\left(\left|F_{o}\right|-\left|F_{c}\right|\right)^{2}\right]$ $\left.\sum w F_{o}{ }^{2}\right]^{1 / 2}$ and $S=\left[\sum w\left(\left|F_{o}\right|-\left|F_{c}\right|\right)^{2} /(m-\right.$ $n)]^{1 / 2}$ (or the $F^{2}$ equivalents)

Method used to calculate $w$
Ratio of maximum least-squares shift to error in final refinement cycle, $(\Delta / \sigma)_{\max }$

Justification of $(\Delta / \sigma)_{\max }$ value if it exceeds 1.0

Maximum positive and maximum negative electron density in final difference Fourier synthesis, $(\Delta \rho)_{\max },(\Delta \rho)_{\min }$

Primary- and secondary-extinction values (if used)

Source of atomic scattering factors and $f^{\prime}, f^{\prime \prime}$ values

All computer programs used (see also $\S 10$ of Notes for Authors)

\section{(f) Diagrams and photographs}

Drawings in black ink or high-quality glazed prints

Cited in text

Typically two per structure (projection of molecule and stereoview or projection of unit-cell packing)

As small as possible consistent with legibility

High information density

Lettering not less than $4 \mathrm{~mm}$ high on International A4 sized $(210 \times 297 \mathrm{~mm})$ or $8 \frac{1}{2} \times 11$ in paper (and pro rata)

Figure captions in separate list

Chemical and structural formulae preferably in camera-ready form

Stereofigures:

One of the two figures per structure

Centre-to-centre separation of $55 \mathrm{~mm}$ or less

Atom labelling on left and right views that remains legible and higher than $1 \frac{1}{4} \mathrm{~mm}$ after reduction

(g) Tables

Not to repeat information given in text or diagrams

Cited in text

Typically two per structure (coordinates and bonding geometry)

Table number and title to be given for each

To occupy minimum space consistent with clarity

To include e.s.d.'s for all derived quantities (especially all varied parameters)

The following generally to be deposited: structure factors, anisotropic thermal parameters, leastsquares planes, unrefined $\mathrm{H}$-atom coordinates

\section{(h) References}

In form: authors' names followed by year of publication

Alphabetic order in reference list

All references in text to be given in reference list and vice-versa

Inclusive page numbers to be given in reference list 
Short-Format Papers should cite essential references under Related literature and give full bibliographic details in reference list

Codens-type notation with volume and initial page number to be used in multi-reference structural papers (see Table)

\section{(i) Units and Nomenclature}

SI units to be used throughout (except for $\AA$ )

Atom labels as $\mathrm{C}(1)$ etc.

Space groups in Hermann-Mauguin notation (Schönflies symbols may be used in addition for molecular symmetry)

Choice of axes as recommended by Kennard, Speakman \& Donnay [Acta Cryst. (1967). 22, 445-449]

Symmetry-equivalent atoms to be denoted as $\mathrm{C}\left(1^{1}\right)$ etc., with symmetry operations defined in terms of equivalent positions

Reflections, planes, directions and forms to be unambiguously distinguished (see Notes for Authors, §8)

Chemical names and formulae to conform to IUPAC rules, including spelling of element names

Acronyms to be defined

Nomenclature of polytypes to conform to Guinier recommendations [Acta Cryst. (1984). A40, 399-404] (j) Data to be deposited

In general:

Structure factors

Anisotropic temperature factors

Least-squares planes and deviations

Calculated $\mathrm{H}$-atom coordinates

Normal intermolecular distances

Tables of non-essential bond lengths and angles

At the Co-editor's discretion:

Details of experimental procedures

Details of mathematical derivations

Lengthy mathematical appendices

Lengthy discussion not of general interest

For macromolecular papers:

Atomic coordinates, thermal parameters and structure factors in machine-readable form with the Brookhaven Protein Data Bank [see Acta Cryst. (1981). B37, 1161-1162; Acta Cryst. (1982). B38, 1050]

For powder-data papers:

Powder data (in standard format - see Notes for Authors, Appendix III) with the JCPDS

Format of deposited material (for all papers other than macromolecular):

Not to exceed A4 size $(210 \times 297 \mathrm{~mm})$ or $8 \frac{1}{2} \times 11$ in

Minimum character height $1.5 \mathrm{~mm}$

Three copies, of good photocopiable quality

Codens for journals frequently referenced in crystallographic papers

Acc. Chem. Res.
ACS Symp. Ser.
Acta Chem. Scand. Ser. A
Acta Chem. Scand. Ser. B
Acta Cryst.
Acta Cryst. A
Acta Cryst. B
Acta Cryst. C
Acta Metall.
Adv. Chem. Ser. (ACS)
Adv. Inorg. Chem. Radiochem.
Adv. Struct. Res. Diffr. Methods
Am. Mineral.
Angew. Chem.
Angew. Chem. Int. Ed. Engl.
Ann. Chim. (Paris)
Ann. Chim. (Rome)
Ann. N.Y. Acad. Sci.
Ann. Phys. (Leipzig)
Annu. Rev. Phys. Chem.
Ark. Kemi
Arzneim.-Forsch.
Atti Accad. Naz. Lincei. Cl. Sci.
Fis. Mat. Nat. Rend.
Aust. J. Chem.
Ber. Bunsenges. Phys. Chem.
Ber. Dtsch. Chem. Ges.
Ber. Dtsch. Chem. Ges. A
Ber. Dtsch. Chem. Ges. B
Biochem. Biophys. Res. Commun.
Biochim. Biophys. Acta
Bioinorg. Chem.
Bioorg. Khim.

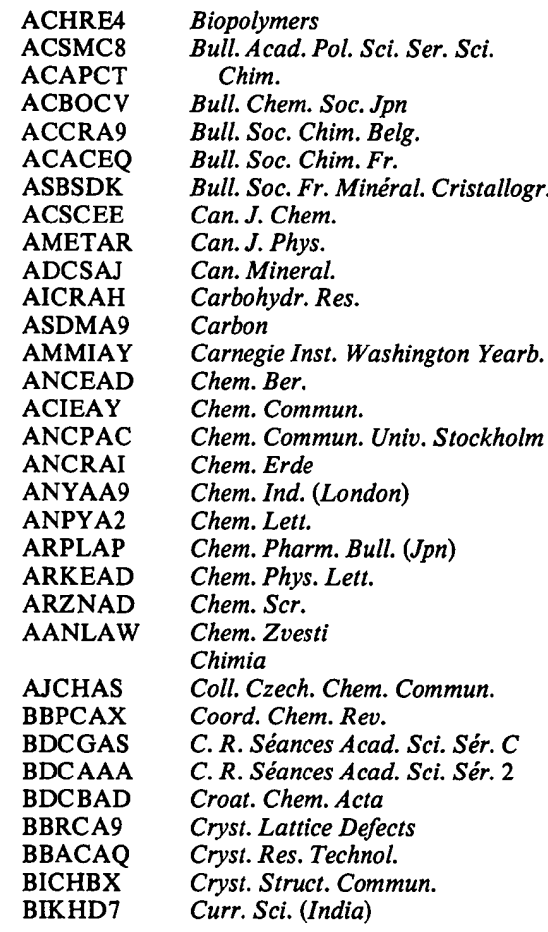

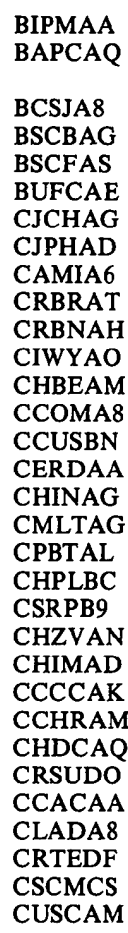

Discuss. Faraday Soc.

Dokl. Akad. Nauk SSSR

Dokl. Akad. Nauk SSSR Ser. Khim.

Dopov. Akad. Nauk Ukr. RSR, Ser. $B$

Eur.J. Biochem.

Experientia

FEBS Lett.

Ferroelectrics

Finn. Chem. Lett.

Fiz. Tverd. Tela (Leningrad)

Fortschr. Mineral.

Gazz. Chim. Ital.

Gold Bull.

Helv. Chim. Acta

Heterocycles

Indian Chem.J.

Indian J. Chem.

Indian J. Phys.

Indian J. Phys. Part A

Indian J. Phys. Part B

Inorg. Chem.

Inorg. Chim. Acta

Inorg. Nucl. Chem. Lett.

Int. J. Pept. Protein Res.

Isr. J. Chem.

Izv. Akad. Nauk SSSR Neorg. Mater.

J. Am. Chem. Soc

J. Appl. Cryst.

J. Biol. Chem.

J. Chem. Phys.
DFSOAW

DANKAS

DASKAJ

DANND6

EJBCAI

EXPEAM

FEBLAL

FEROA8

FCMLAS

FTVTAC

FMRLAL

GCITA9

GLDBBS

HCACAV

HTCYAM

ICLJAG

IJOCAP

IJPYAS

INJADP

IJPBDU

INOCAJ

ICHAA3

INUCAF

IJPPC3

ISJCAT

IVNMAW

JACSAT

JACGAR

JBCHA3

JCPSA6 
J. Chem. Res. Synop.

J. Chem. Soc. A

J. Chem. Soc, $B$

J. Chem. Soc. Chem. Commun.

J. Chem. Soc. Dalton Trans.

J. Chem. Soc. Perkin Trans. 1

J. Chem. Soc. Perkin Trans. 2

J. Chim. Phys. Phys. Chim. Biol.

J. Coord. Chem.

J. Cryst. Growth

J. Cryst. Mol. Struct.

J. Crystallogr. Spectrosc. Res.

$J$. Electrochem. Soc.

J. Electron Mater.

J. Fluorine Chem.

J. Heterocycl. Chem.

J. Inclusion Phenom.

$J$. Inorg. Biochem.

J. Inorg. Nucl. Chem.

J. Less Common Met.

J. Magn. Reson.

J. Mater. Sci.

J. Mol. Biol.

J. Mol. Spectrosc.

J. Mol. Struct.

J. Nat. Prod.

J. Nucl. Mater.

J. Org. Chem.

J. Organomet. Chem.

J. Pharmacol. Exp. Ther.

J. Phys. C

J. Phys. F

J. Phys. Chem.

J. Phys. Chem. Solids

J. Phys. Lett.

J. Phys. Soc. Jpn

J. Polym. Sci.

J. Polym. Sci. Polym. Chem. Ed.

J. Prakt. Chem.

J. Raman Spectrosc.

$J$. Solid State Chem.

J. Struct. Chem. (Engl. Trans.)

Jpn.J. Appl. Phys.

Jpn. J. Appl. Phys. Part 1

Jpn. J. Appl. Phys. Part 2
JRPSDC

JCSIAP

JCSPAC

JCCCAT

JCDTBI

JCPRB4

JCPKBH

JCPBAN

JCCMBQ

JCRGAE

JCMLB5

JCREDB

JESOAN

JECMA5

JFLCAR

JHTCAD

JOIPDF

JIBIDJ

JINCAO

JCOMAH

JOMRA4

JMTSAS

JMOBAK

JMOSA3

JMOSB4

JNPRDF

JNUMAM

JOCEAH

JORCAI

JPETAB

JPSOAW

JPFMAT

JPCHAX

JPCSAW

JPSLBO

JUPSAU

JPSCAU

JPLCAT

JPCEAO

JRSPAF

JSSCBI

JSTCAM

JJAPA5

JAPNDE

JAPLD8
Justus Liebigs Ann. Chem.

Khim. Prir. Soedin.

Koord. Khim.

Kristallografiya

Krist. Tech.

Life Sci.

Makromol. Chem.

Mater. Res. Bull.

Mater. Sci.

Mater. Sci. Eng.

Mineral. J.

Mineral. Mag.

Mol. Cryst. Liq. Cryst.

Monatsh. Chem.

Natl Bur. Stand. US Circ.

Natl Bur. Stand. US Monogr.

Natl Bur. Stand. US Spec. Publ.

Natl Bur. Stand. US Tech. Note

Nature (London)

Naturwissenschaften

Neues Jahrb. Mineral. Abh.

Neues Jahrb. Mineral. Monatsh.

Nouv. J. Chim.

Organometallics

Philos. Mag.

Physica A (Amsterdam)

Physica $B \& C$ (Amsterdam)

Physica (Utrecht)

Phys. Kondens. Mater.

Phys. Rev. B: Condens. Matter

Phys. Rev. B: Solid State

Phys. Status Solidi

Phys. Status Solidi A

Phys. Status Solidi B

Pol. J. Chem.

Polyhedron

Pramana

Proc. Natl Acad. Sci. USA

Proc. R. Soc. London Ser. A

Proc. R. Soc. London Ser. B

Prog. Inorg. Chem.

Prog. Med. Chem.

Q. Rev. Chem. Soc.

Recl: J. R. Neth. Chem. Soc.
JLACBF

KPSUAR

KOKHDC

KRISAJ

KRTEAW

LIFSAK

MACEAK

MRBUAC

MSCJDS

MSCEAA

MJTOAS

MNLMBB

MCLCA5

MOCMB7

NBSCAA

NBSMA6

XNBSAV

NBTNAE

NATUAS

NATWAY

NJMIAK

NJMMAW

NJCHD4

ORGND7

PHMAA4

PHYADX

PHBCDQ

PHYSAG

PKOMA3

PRBMDO

PLRBAQ

PHSSAK

PSSABA

PSSBBD

PJCHDQ

PLYHDE

PRAMCI

PNASA6

PRLAAZ

PRLBA4

PIOCAR

PMDCAY

QUREA7

RJRSDK
Recl Trav. Chim. Pays-Bas

RTCPA3

Rev. Chim. Minér.

Rev. Sci. Instrum.

Ric. Sci.

Rocz. Chem. Trans.)

S. Afr.J. Chem.

Schweiz. Mineral Petrogr. Mitt.

Science

Solid State Commun.

Sov. Phys.-Crystallogr. (Engl. Trans.)

Sov. Phys.-Solid State (Engl. Trans.)

Spectrochim Acto

Spectrochim Acta Part A

Struct. Bonding (Berlin)

Suom. Kemistil. B

Tetrahedron

Tetrahedron Lett.

Theor. Chim. Acta

TMPM Tschermaks Mineral.

Petrogr. Mitt.

Trans. Am. Crystallogr. Assoc.

Trans. Faraday Soc.

Trans. Metall. Soc. AIME

Transition Met. Chem. (N.Y.)

Trermaks Mineral. Petrogr. MTAG

Mitt.

Z. Anorg. Allg. Chem.

ZAACAB

$Z$. Anorg. Chem.

Z. Elektrochem.

Z. Kristallogr.

$Z$. Metallkd.

Z. Naturforsch. Teil $A$

$Z$. Naturforsch. Teil $B$

Z. Phys. Chem. (Frankfurt am

Main)

Z. Phys. Chem. (Leipzig)

Zh. Neorg. Khim.

Zh. Obshch. Khim.

Zh. Strukt. Khim.

ZACMAH

ZEELAI

ZEKRDZ

ZEMTAE

ZTAKDZ

ZNBAD2

ZPCFAX

ZPCLAH

ZNOKAQ

ZOKHA4

ZSTKAI

The required form of the Codens-type notation for references in multi-reference structural papers is ACSCEE 411 (representing page 1 of Volume 41 of the journal Acta Cryst. Section C). 